\title{
Dermatitis por radiation recall inducida por gemcitabina
}

\section{Sr Director:}

La dermatitis por radiation recall se refiere a una reacción inflamatoria cutánea en zonas que habían recibido radioterapia previamente, y desencadena tras la exposición a un agente precipitante, fundamentalmente taxanos y antraciclinas. Presentamos un caso inusual de dermatitis por radiation recall inducida por gemcitabina, uno de los fármacos actualmente más usado en distintos tipos de tumores, en una paciente con cáncer de mama y que había recibido radioterapia sobre las metástasis óseas en la zona afectada.

Mujer de 51 años de edad sin antecedentes personales de interés, fue diagnosticada en abril de 1988 de un carcinoma lobulillar infiltrante de mama izquierda pT2N1M0 moderadamente diferenciado con expresión positiva para los receptores hormonales de estrógenos en el $100 \%$ de las células, y para los progestágenos en el $40 \%$ de las células, c-erbB2 negativa. La paciente fue tratada mediante mastectomía radical más 6 ciclos de quimioterapia adyuvante mediante un esquema de adriamicina, 5fluorouracilo y ciclofosfamida. Posteriormente recibió tamoxifeno durante 5 años, y siguió revisiones periódicas. En junio de 2004 acude por dolor progresivo de meses de evolución a nivel de la rodilla y parte inferior del muslo izquierdo con impotencia funcional para caminar. Se realizó una radiografía simple y una tomografía axial computerizada con ventana ósea de la zona, que informaban de la presencia a nivel del fémur izquierdo, en cóndilo medial, de varias lesiones líticas que destruían la cortical con masa de partes blandas, compatible con metástasis ósea (Figura 1). La gamma grafía ósea describía lesiones en $4^{\circ}$ arco posterior de costilla derecha, $8^{a}$ vértebra dorsal y la ya citada en fémur iz-

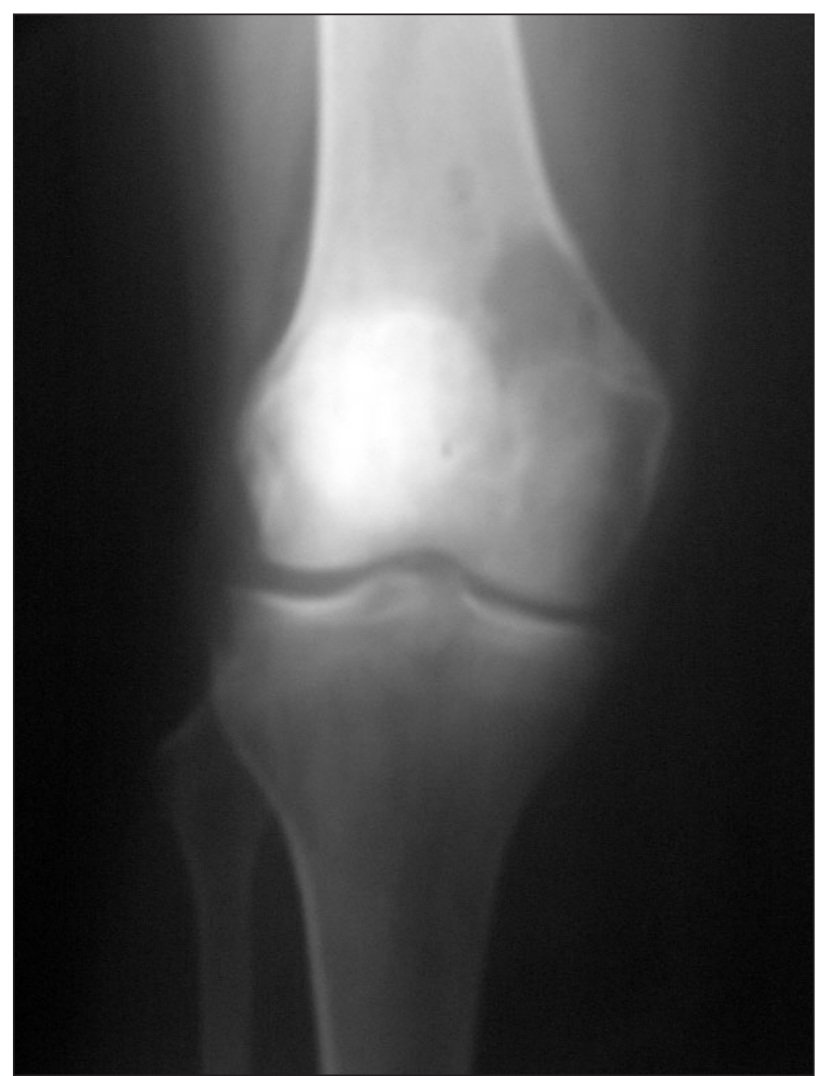

Figura 1. Lesión ósea lítica en cóndilo del fémur izquierdo.

quierdo, todas compatibles con metástasis. El resto del estudio de extensión fue negativo. La paciente recibió radioterapia local en dicha zona con una dosis de 15 Gy en 3 sesiones, con importante mejoría clínica, y a continuación se pautó tratamiento hormonal con inhibidores de aromatasa y difosfonatos. En septiembre de 2005 se evidenció progresión ósea en la gamma grafía de control, con aumento del marcador tumoral CA15.5 y aparición de varios nódulos pulmonares que sugerían metástasis pulmona- 


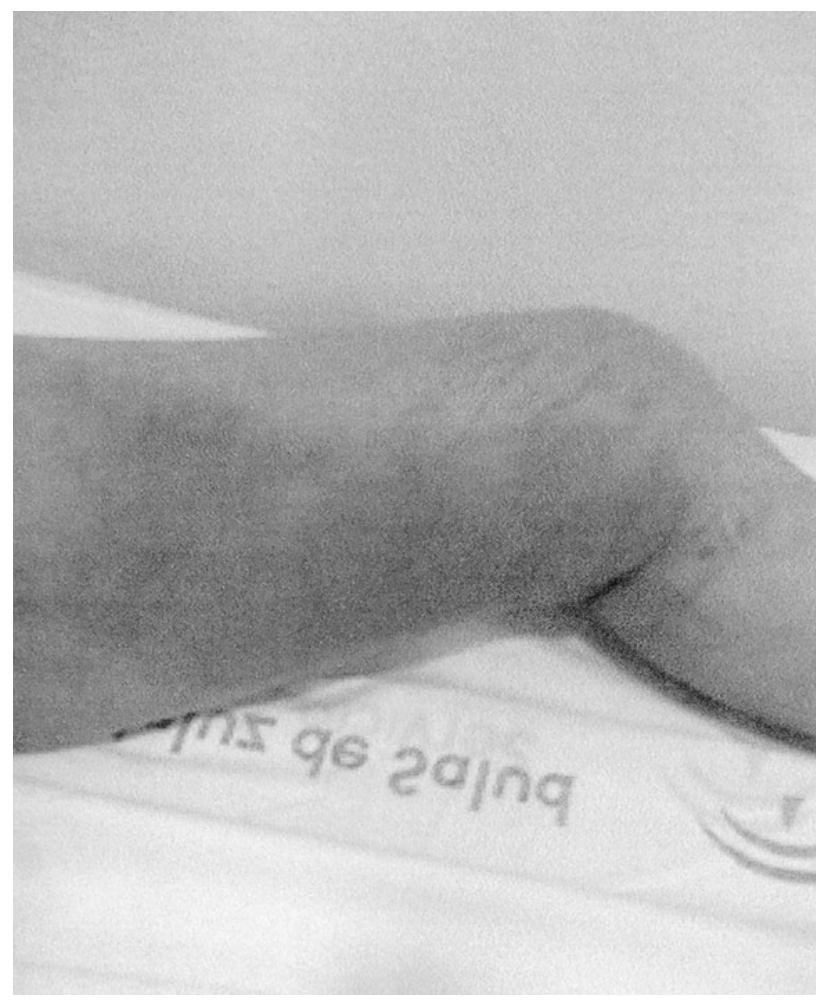

Figura 2. Dermatitis por radiation recall sobre muslo izquierdo, previamente irradiado.

res. Se inició tratamiento quimioterápico con gemcitabina semanal $1200 \mathrm{mg} / \mathrm{m}^{2}$. Tras la cuarta infusión de gemcitabina, la paciente consultó por una lesión eritematosa de bordes bien definidos, con prurito y dolor local a nivel de la cara anterior del muslo izquierdo, zona que había sido irradiada 14 meses antes (Figura 2), sin fiebre ni otros síntomas asociados. Dicho efecto se había producido en las dos administraciones previas pero con menor intensidad. La paciente no refería ningún otro síntoma acompañante. El resto de la exploración física fue normal así como la analítica y una ecografía doppler de la extremidad inferior afectada. Se interrumpió el tratamiento con gemcitabina y se pautó tratamiento con corticoides vía oral, desapareciendo la lesión dos semanas más tarde.

La dermatitis por radiation recall es una reacción inflamatoria cutánea en zonas expuestas a la radioterapia previamente, que se encontraban quiescentes antes del recall, y que aparece tras la administración posterior de un agente precipitante ${ }^{1}$. El inicio de los síntomas suele ocurrir entre días y semanas después de la exposición a la droga precipitante, aunque no hay un intervalo de tiempo fijo establecido, pudiendo incluso aparecer años más tarde. Entre la manifestaciones cutáneas podemos encontrar erupciones maculopapulares, formación de vesículas, descamación o necrosis cutánea. En ocasiones puede afectar a órganos internos produciéndose mucositis orofaringea, esofagitis, pneumonitis o miositis. Una amplia variedad de fármacos se han relacionado con este fenómeno, destacando sobre todo las antraciclinas y los taxanos. En menor medida se han comunicado casos con gemcitabina ${ }^{2-6}$, metotrexate, capecitabina, vinblastina, bleomicina, oxaliplatino, etopósido, hidroxiurea, melfalán, interferón $\alpha$ o tamoxife$\mathrm{no}^{2}$. La causa de este fenómeno es desconocida, si bien se ha especulado sobre la influencia de las radiaciones sobre los procesos farmacodinámicos de determinados fármacos o sobre las células stem cells epiteliales, unido a la propia ideosincrasia de las reacciones de hipersensibilidad de algunos pacientes ${ }^{7}$. El tratamiento consiste en el cese de la administración del agente responsable, y se suele pautar corticoides tópicos o sistémicos, según la intensidad clínica de la reacción.

Gemcitabina (2',2'-difluorodeoxycytidine), es un antimetabolito pirimidínico desarrollado como análogo fluorado de la deoxicitidina. En el interior de la célula es fosforilada a los nucleósidos activos difosfato (dFdCDP) y trifosfato ( $\mathrm{dFdCTP})$, los cuales al incorporarse al ADN provocan una terminación de su cadena. El dFdCDP inhibe la enzima ribonucleótido reductasa, reduciendo la síntesis de desoxinucleósidos trifosfatos, en especial de dCTP, necesarios para la síntesis de ADN. Ambos mecanismos inhiben la síntesis de los ácidos nucleicos induciendo finalmente la apoptosis. Gemcitabina es un fármaco con un amplio espectro de actividad clínica antitumoral (mama, pulmón, vejiga, ovario, y páncreas), junto a un perfil de tolerancia adecuado en su administración semanal, siendo la mielotoxicidad la principal toxicidad limitante de dosis ${ }^{8}$. El mecanismo por el cual gemcitabina induce radiation recall no es bien conocido9. Gemcitabina se ha mostrado como un potente agente radiosensibilizante cuando se administra concomitante con la radioterapia, sin embargo se desconoce si esta característica actúa como factor desencadenante ${ }^{10}$.

Por tanto, a pesar de la rareza de este fenómeno asociado a la gemcitabina, debemos considerar la posibilidad de su aparición e identificación en pa- 
cientes que recibieron radioterapia previamente, $y$ diferenciarlo de otras entidades clínicas que pueden también afectar la piel como algunas reacciones de hipersensibilidad, episodios de trombosis venosas o infecciones cutáneas.

\section{A. Sánchez-Muñoz ${ }^{1}$, A. M. García Tapiador ${ }^{1}$, R. Dueñas García ${ }^{1}$ A. L. Ortega Granados ${ }^{1}$, E. Martínez Ortega ${ }^{1}$, M. Matea Moreno ${ }^{2}$ ${ }^{1}$ Servicio de Oncología Médica \\ ${ }^{2}$ Servicio Medicina Interna Hospital Médico Quirúrgico Ciudad de Jaén Jaén (España)}

Correspondencia:

Dr. A. Sánchez Muñoz

C/ Poeta Francisco Coronado y Delicado, $4-3^{\circ} \mathrm{C}$ E-29011 Málaga

asmoncomed@yahoo.es

\section{Bibliografía}

1. Camidge R, Price A. Characterizing the phenomenon of radiation recall dermatitis. Radiother Oncol 2001; 59: 237245.

2. Burstein H. Radiation recall dermatitis from gemcitabine. J Clin Oncol 2000; 18: 693-694.

3. Bar-Sela G, Beny A, Berman R, Kuten A. Gemcitabine induced radiation recall dermatitis: case report. Tumori 2000; 87: 428-430.

4. Castellano D, Hitt R, Cortes-Funes, et al. Radiation recall induced by gemcitabine. J Clin Oncol 2000; 18:696-696.

5. Jeter M, Pasi J, Brooks S, et al. Gemcitabine-induced radiation recall. Int J Radiat Oncol Biol Phys 2002; 53: 394 400.

6. Schwartz BM, Khuntia D, Kennedy AW, Markman M. Gemcitabine-induced radiation recall dermatitis following whole pelvic radiation therapy. Gynecol Oncol 2003; 91: 421-422.

7. Friedlander PA, Bansal R, Schwartz L, et al. Gemcitabinerelated radiation recall preferentially involves internal tissue and organs. Cancer 2004; 100(9): 1793-1799.

8. Tonato M, Mosconi AM, Martin C. Safety profile of gemcitabine. Anticancer Drugs 1995; 6 (suppl 6): 27-32.

9. Kitani H, Kosaka T, Fujihara T, et al. The "recall effect" in radiotherapy: is subeffective, reparable damage, involved? Int J Radiat Oncol Biol Phys 1990; 18: 689-695.

10. Lawrence TS, Eisbruch A, McGinn CJ, et al. Radiosensitization by gemcitabine. Oncology 1999; 13: 55-60. 